CP, 2018, Vol.7 - No13, pp. 9/26 ISSN 2014-6752. Girona (Catalunya). Universitat de Girona. FRISIELLO, Antonella y ACTIS-GROSSO, Rossana: Global iniciatives to locally explore the user experience. The case of the Turin World Usability Day. Recibido: 11/12/2017 - Aceptado: $8 / 3 / 2018$

\title{
Global initiatives to locally explore the user experience The case of the Turin World Usability Day
}

\author{
Autoras \\ Antonella Frisiello \\ https://orcid.org/0000-0002-6600-0068 \\ Istituto Superiore Mario Boella, Turin, Italy. \\ frisiello@ismb.it, @fant0nella \\ Rossana Actis-Grosso \\ https://www.researchgate.net/profile/Rossana_Actis-Grosso \\ Department of Psychology, Università degli Studi di Milano-Bicocca \\ rossana.actis@unimib.it
}

\section{Resumen:}

La literatura muestra cómo la tecnología y el progreso científico requieren y favorecen el enfoque multidisciplinario. Entre las áreas híbridas de estudio e intervención, la Experiencia del Usuario (UX) actualmente está despertando una nueva fase de interés. Enfocada en la relación entre personas y sistemas tecnológicos, la UX está ampliando progresivamente su audiencia: además de la academia y la industria, las administraciones públicas, las instituciones educativas, las empresas de nueva creación, los trabajadores independientes están volcando su atención hacia ella. Este trabajo presenta una reflexión sobre una iniciativa global, el Día Mundial de la Usabilidad (WUD), organizada a nivel local. Los datos recopilados sobre los contenidos y la audiencia de las 3 primeras ediciones del Turin WUD resaltaron la importancia, las ventajas y las dificultades de organizar eventos presenciales para promover un cruce e intercambio de conocimiento productivo entre profesionales desde diferentes disciplinas.

Palabras Clave: Experiencia de usuario, ergonómico, diseño, multicidisciplinareidad, red profesional

\section{Abstract:}

Literature shows how technology and scientific progress require and facilitate an multidisciplinary approach. Among the hybrid areas of study and intervention, the User Experience (UX) is currently experiencing a renewed phase of interest. Focusing on the relationship between people and systems, the UX is progressively widening its stakeholders' audience: over academy and industry, public administrations, educational institutions, start-ups, freelancers are turning their attention to it. This work presents a reflection based on a global initiative, the World Usability Day, that authors organized in locally. The data collected on contents and audience of the first 3 editions of Turin WUD highlights the importance, advantages and difficulties of organizing face-to-face events to promote cross-fertilization and knowledge sharing among professionals.

Keywords: User Experience, Ergonomics, Design, Multidisciplinary, Professional networking 


\section{Introduction}

The scientific and technological evolution of recent years are bringing important advancements in several fields, with the consequence of a knowledge as wider and more accessible than ever. It has been observed that interdisciplinary research counter-poses different forms of investigation, creating space for novel fields of study, which are continuously developing [Solomon et al., 2016].

User experience (UX) can be considered one example of these hybrid areas, being focused on the connection between two of the core issues of human sciences: "the experience" and "the user". These two issues are now common objects of interest for different fields, such as technology $(\mathrm{HCl})$, economy (marketing), engineering (design) and psychology [Milburn et al., 2015[, [Law, 2007]. The UX investigates, designs and assesses the multiple aspects concerning the interaction between a person and a system (that can be a product, a service, a digital application, an organization). UX is thus an umbrella term used to refer and link complementary concepts, such as usability, user interface, interaction design, customer experience, service design, ergonomics. The core principle is the adaptation of products and services to people - and not, as it often happens, the contrary-. UX is thus wider than usability, although the two concepts are strictly connected. Enhancing the usability of a digital artefact, in addition to facilitating its use, aims at preventing errors and mistakes. This is especially important in safety critical areas, such as medical applications, but it is critical also in everyday life, besides enriching the satisfaction during the use. In addition to this, designing an experience requires that tools imply to shape activities, processes are shaped to meet perceptual, cognitive, emotional, social and cultural characteristics of target people they are designed for [Bader, 2017], [Hassenzahl et al. 2006].

UX reveals a multidisciplinary nature. Achieving high-quality UX is a challenge that scientific research and companies, cope with by merging multiple perspectives and skills [Mayhew, 2008]. The growing and spreading of a new design culture, focused on the specific knowledge of users is well attested by a growing number of scientific papers, technical publications, groups of interest, as well as blogs on the main social media and web-sites of companies, influencers, professionals or simply people who, having discovered this new and fruitful way of designing products, start disseminating this idea.

In trying to map and monitor the evolution of the UX at a global level, it is important to understand how (and how much) UX is applied in the local professional communities. The present work moves from the need (i) to look at the scene of the UX at a local scale, understanding how it is diffused and applied, identifying main stakeholders, and (ii) to better understand the local UX sector in terms of methodology and best practices, trends as well as uncovered areas of development that could suggest supporting initiative.

The organization of a local event connected with a global network of UX specialists has been the base for authors to address the depicted goals. The paper presents the context and details of the organization of the Turin World Usability Day, the local chapter of a global event, that has allowed addressing at the same time several goals:

- to encourage the exchange of knowledge and best practices among researchers and professionals coming from several backgrounds but working on UX in different fields and sectors; 
- to stimulate the active discussion and possibly collaborations among participants;

- to facilitate the match between the educational offer and the professional demand.

Three editions of the event have allowed to collect information helpful to map the local scene of the UX, including stakeholders, skills and fields for application. The Turin WUD has been organized in 2017 as well, although data for this year are still not fully available.

The first three editions of the event have been identified as object of investigation and the results and lessons learnt of post-hoc analysis here presented, with a focus on some data about speakers, audience and contents, together with observations of the organizers.

\subsection{Brief and incomplete history of ux and its origins}

Traditionally the area of encounter among technology and humans has been studied by experts in the field of Human-Computer Interaction $(\mathrm{HCl})$. This area of research comes to light during the First World War, with the aim of optimizing the interface of military equipment and increasing the efficiency and reliability of the two macro-systems in action: the human agent and the machine [Olson and Kellogg, 2014]. The core concepts of $\mathrm{HCl}$ were then applied in peacetime to other sectors, such as civil aviation and manufacturing, focusing primarily on different types of workplaces. Over years, technology passes from being a core professional commodity to be accepted as private appliance and today personal assistant. Within the man-machine dyad, the human being becomes even more important. A number of industrial sectors, such as automotive, household, electronics and services create applied research centres and laboratories dedicated to the Human Centred Design.

The aim is to understand and maximize the ease of use and customers' satisfaction during the experience of use. This novel field of study is focused on understanding the interaction among humans and systems, in order to optimize human well-being and overall system performance. Human Factors, or Ergonomics, refer to the design and evaluation of tasks, jobs, products, organizations, environments and systems in order to make them compatible with the needs, abilities and limitations of people [IEA, 2010](1). In 1986 Donald Norman contributes to confirm the central role of the human side within the interaction with technology in the book "User centred system design. New perspectives on human-computer interaction $(\mathrm{HCl})$." Over time the study of the interaction between persons and systems expanded from workplaces to processes and tools, with a specific important focus on the digital world.

Innovation technology has entered reliably in all areas of life and work. According to Norman, technology potentially makes our daily life more comfortable and pleasant, but at the same time it adds complexity and complication. The resulting paradox, where complexity and difficulties are inevitable when increasing the number of features, can be minimized by a good design [Norman, 2002].

The quality of the interaction between people and systems has been defined and then standardized by international organizations. Usability is the extent to which a product can be used by "specified users to achieve specified goals with effectiveness, efficiency and satisfaction in a specified context of use" [ISO 9241:2010]. Recently this concept has been extended and included in the wider concept of User Experience. The focus on the usage and the possibility to easily accomplish a goal has been widen to make more relevant the pleasure of use and to 
extend the time-perspective of the usage: the experience starts before the use (engagement), takes place during the use and continues after the use (appropriation), as showed in the following figure. According to Roto et al. [2011], the overall UX, rather than being a transient emotion during the interaction, includes also the phases outside the interaction, and the emotions raised during the whole process (Fig. 1). In brief, UX shifts the focus from the inner workings of a product or service, to the interaction with persons, with their affects, sensations, meanings and values [Garrett, 2011].

Figure 1. From the usability to the user experience [Source: Franzreb and Franzreb, 2016]

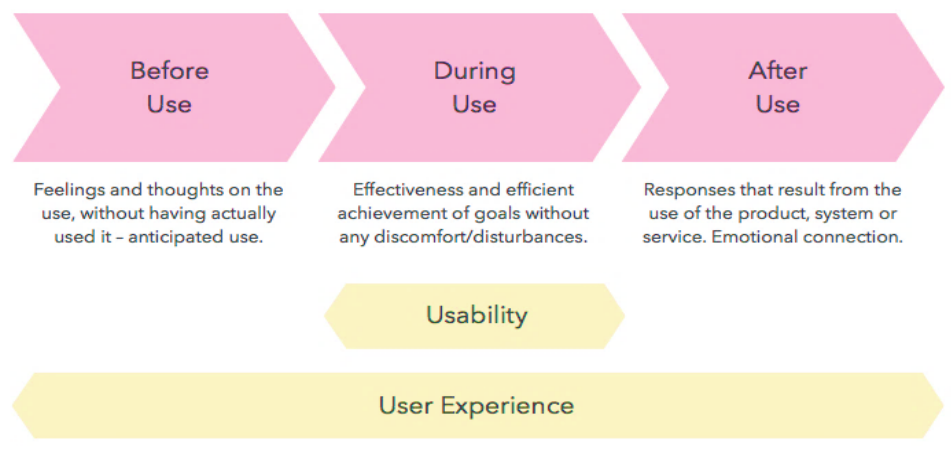

The User Experience is a quite recent construct that has been widely embraced by the $\mathrm{HCl}$ scientific community. Moreover, it is becoming much sought after by companies, enterprises, start-ups in a wide range of sectors. Different areas of activity interpret and work on several aspects of the UX, which is becoming a key asset enabling innovation. In the business field, UX helps organizations to understand what is valuable for the customers, to increase customers' satisfaction and finally to improve the sales. In the research field, UX helps projects and researchers to stay stick to the real world, working on real data; it encourages multidisciplinary and a systemic approach, providing techniques to elaborate and share visions on the future scenarios [Malouf, 2016].

UX is now considered as a strategic component of projects. Both scientific research and professional practices introduce the UX since the early stage of the design process, because adapting tools and contexts to humans brings an obvious benefit. Besides, academy, research centres and companies start to implement Human Centred Design (HCD) as an approach to improve usability and UX. Over time, the Human Centred Approach and related disciplines such as the Human Computer Interaction, Human Factors and Ergonomics have been moved from the laboratories to the running processes of companies and, more recently, of public administrations (Lachner, 2016).

The theoretical evolution has brought to a progressive diffusion and application of the UX methods from the research to the business, that currently recognize and aim at achieving high quality UX, user satisfaction and the economic advantage deriving from iterative and participatory methodologies able to prevent errors and save resources. The growing stakeholders' audience influence the research trajectory and results. Novel methodologies come from pro- 
ductive sectors, requiring agile techniques such as the "discount usability" - coined by Nielsen in 1989 [Nielsen, 2009] - or the more recent Design Sprint framework launched by Google(2).

The UX and UX designers are assuming a key role into an increasing number of fields, for the capability to address the market and the business goals with a human centred perspective, not technology driven, but based on a combination of empathy, problem solving and creativity. Big companies like Apple, Amazon, Google have emphasized the role of the UX, so that today there are over 150,000 open positions for UX designer [Bloc, 2015]. The scenario is very dynamic: Fast Company foresees and defines 18 new profiles, as evolution of UX design for the near future [Labarre, 2016]. Nevertheless, including the UX research and design into development phases is not easy: it implies organizational decisions, individuals' attitudes and tools of communication, and new skills to be included. Even now, the difficulty to assume a user-centred perspective results one of the most relevant obstacles.

\subsection{One of the UX initiatives in the world}

As the UX sector is growing, it is possible to encounter an increasing number of initiatives, associations, and groups, dedicated to exchange practices, foster knowledge, promote cooperation. At local level, the Italian Society of Ergonomics (SIE)(3) is one of the associations focusing on the UX among its areas of interest. Founded in 1968, SIE aims at promoting the development and diffusion of the Human Factors study and Ergonomic approach application, in cooperation with local and international entities, ranging from the academy to the business.

In order to comply with this mission, the SIE Group of Interest in Cognitive Ergonomics decided to join the global initiative promoted by the User Experience Professional Association (UXPA)(4), namely the World Usability Day (WUD)(5). WUD is an annual event, promoted on global scale since 2005, by a community of professionals of industry, education, public administration, research. All have in common the goal of working for making technology a promotion factor for people, enhancing the quality of life and facilitating the personal expression, realization and inclusion as active citizens at a global level (6).

SIE has joined the WUD in 2014, organizing the first WUD in Turin. Dissemination, professional networking and cross-fertilization were the objectives of an operation that keeps on being organized and that explicitly draws trajectories aimed at multidisciplinary approach. Some key elements characterize the formula of the Turin WUD:

Multidisciplinary: the mix of experience, skills and sectors is the main feature for both speakers' panel and the audience. In order to promote the exchange and dissemination of knowledge and practices, especially between the research and enterprises, the program of the event is based on the presence of invited speakers coming from several fields: academy, research and innovation as well as industry and, recently, public administration. Moreover, the panel includes both young and senior speakers, bringing theoretical and applicative contributions. Research results, pre-commercial projects and running services are selected to be presented in order to offer an outlook of the state of the art on the challenge of the year. The program always includes an introductory keynote, aimed at framing the topic and 
set the field of work for the heterogeneous audience.

The target audience includes people studying and working at any level on the UX, such as researchers, professors and students, developers, graphic designers, copywriters, start-uppers, freelancers, managers, decision makers... The variety of background and job is one of the asset of the event.

Experience: thematic workshops, conducted by selected professionals, offer experiential training sessions, where participants cooperatively learn and work on trending topics related to the UX and Human Centred Approach.

Location: as part of the event design, the location is chosen accordingly with the topic of the year. The idea to move the event in different locations meets the need of creating a strong relationship with the territory, local entities, projects and people. Location contributes to depict the big vision of a situated event, better framing the challenge, the values, and the objectives of the initiative.

On this basis, SIE, in close cooperation with academic and industry institutions (such as the Politecnico di Torino, Università di Torino, Università di Milano Bicocca, TIM, Unesco), launched and organized the first three editions of the Turin WUD. Each edition has been designed in accordance with the main topic that UXPA set as a challenge, to invite and stimulate the UX community to organize events around the world with no restrictions on the format. In the following, the three challenges are presented in brief, as per the Turin WUD organizers set them up. The following texts come from the websites of the events and have been used as call for participation.

\section{WUD 2014. User engagement}

In WUD 2014 the engagement has been considered the ultimate challenge in the field of the User Experience when applied to the pervasive digitalization and the consequences it brings to ourselves and our daily activities, both professional and personal. Catching and keeping the user's attention live, even when fragmented in micro-interactions; designing meaningful and effective activities to be done on a plethora of products, apps, services we are using every day; integrating into the design process individual, contextual and technological issues are some of the open issues that framed the Turin WUD 2014 entitled "Exploring the Engagement".

The event was held at the incubator of the innovative start-ups of the Polytechnic of Turin. The venue, placed in the heart of the university campus, was especially successful in terms of dissemination impact: it has allowed to propose and invite the most important group of technological start-ups of the city to an event on the UX, at that time, nearly neglected both by enterprises and academic courses.

In 2014, 98 World Usability Days was held in 35 countries around the world, 2 events in Italy (Turin and Rome).

\section{WUD 2015. Innovation.}

The innovation is a so wide and broad phenomenon that was very difficult to interpret, for the event of 2015. As organizers we provided a definition of innovation as a dynamic process able to bring solutions and opportunities to grow as individuals and community, aware of the Zeitgest and epochal changes. UX focuses on this concept of innovation, promoting people driven - instead of technology driven - processes. In addition to this, the attitude towards 
the assessment drives the UX to pursue effective, efficient and pleasant experiences, not only novel ones. A human-centric innovation has been the benchmark for professionals and researchers coming from fields related to Innovation technology and experiencing a perspective shift. The 2015 Turin WUD was hosted by the first co-working venue of the city, a very lively professional hub, not related to the academic world but active on innovation and creativity, emerging at a small scale with freelancers and micro-enterprises but working on a macro-scenario with innovative models of cooperation.

In 201591 World Usability Days was held in 31 countries around the world, 2 events in Italy (Turin and Rome).

\section{WUD 2016. Sustainability}

The challenge 2016 aimed at intercept the attention of the community on the most urgent and global issue. Sustainability refers to environmental emergency first. We decided to focus the Turin WUD on the human activities behind the lack of sustainability and identify in an economic perspective the area where explore possible contribution in terms of Human centred design and UX. The paradigm of the Circular Economy has been the area where novel sustainable solutions are emerging and where the UX is called to play a relevant role concerning the Users' participation, very critical factor to succeed.

The focus on Sustainability and Circular Economy has brought the event to an institutional venue, offered by the University of Turin, that allowed to engage and involve important public institutions od the city.

In 201673 World Usability Days was held in 24 countries around the world, 3 events in Italy (Turin, Rome and Milan).

\section{The Turin wud as object of study}

The WUD initiative meets at different scales goals of dissemination, discussion, sharing, cooperation. In particular, the main goals addressed are:

- $\quad$ Creating opportunities of cross-fertilization among disciplines and among research and enterprises, as well as public administrations.

- Promoting active discussions on UX related topics, fostered by the perspectives and backgrounds represented in a heterogeneous community.

- Getting closer education and work, universities and companies, in a bidirectional dissemination path, based on the mutual exchange and raising further developments in the job market.

Since the first Turin WUD edition, it has been clear that it would also be an interesting object of study. As organizers of the event, we have assumed it as a living platform to better know the local scene of the UX, in terms of actors, practices and methodologies, trends and domains. Several questions have driven the investigation. In which sectors the UX is more applied? How do different organizations define and implement UX? Are there common theoretical models and methodologies? How do different organizations apply them? In which direction the UX is evolving? Are there gaps to be filled in terms of education and dissemination? 


\subsection{Methodology and results}

In three years several kinds of information from different sources have been collected, concerning the speakers, the participants and presented contents. Data come from the organization of the events, that recorded every detail on the participants and talk. Moreover, we will present an extraction of some relevant data from a satisfaction surveys given to participants at the end of each edition. Even if no data collection tools have been specifically designed for research purposes, observation, content analysis and the collection of data relative to the general audience, could be considered a partial answer to our initial questions, helping to understand how UX is intended in the local scene. In particular, the first part of the following data, besides depicting the sample analyzed, are helpful to understand the local scenario in which UX is applied.

\section{The local UX scene}

In order to deepen and learn more about sectors and organizations active on the UX, information on speakers and participants of the 3 editions have been anonymized and elaborated. As networking and dissemination initiatives we wonder to know more about the sectors and organizations represented.

In three editions of the Turin WUD, 77 speakers were invited to outline, deepen, analyse the UX in all its facets. In the following charts, the aggregated data on the speakers' panel of the 3 years are shown. Over years, speakers have changed a lot (Fig. 2). Regarding the gender, the speakers' panel has changed from the majority of women in 2014 to a majority of men in 2016. Concerning the background, the presence of psychologists and communication scientists remains relevant, confirming the humanistic set-up of the event (Fig. 3 ). The attendance of research institutions and companies varies according with the topic and the venue, able to "activate" different groups and industry sectors (Fig. 4). In general, big companies (multinational corporations and industries) have been firmly active in bringing their cutting-edge projects. The peak of small and medium enterprises (SMEs) is registered in 2015, the year dedicated to innovation. This suggests how a humanistic approach to technology innovation is ridden by more lean organizations. The Public Administration (PA), absent from the early editions, appears at the third edition, stimulated by the topic of sustainability, which is fundamental in designing for policies and services. 
FRISIELLO, ANTONELLA y ACTIS-GROSSO, ROSSANA: Global initiatives to locally explore the user experience The case of the Turin world usability day

Figure 2. Speakers of the Turin WUD 2014-2016. Gender (Source: SIE Piemonte)

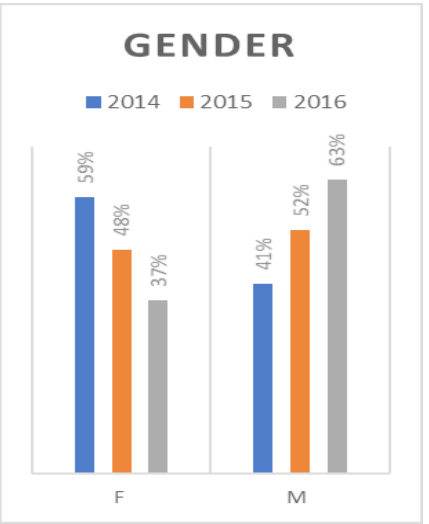

Figure 3. Speakers of the Turin WUD 2014-2016. Background WUD 2014-2016. (Source: SIE Piemonte)

\section{BACKGROUND}
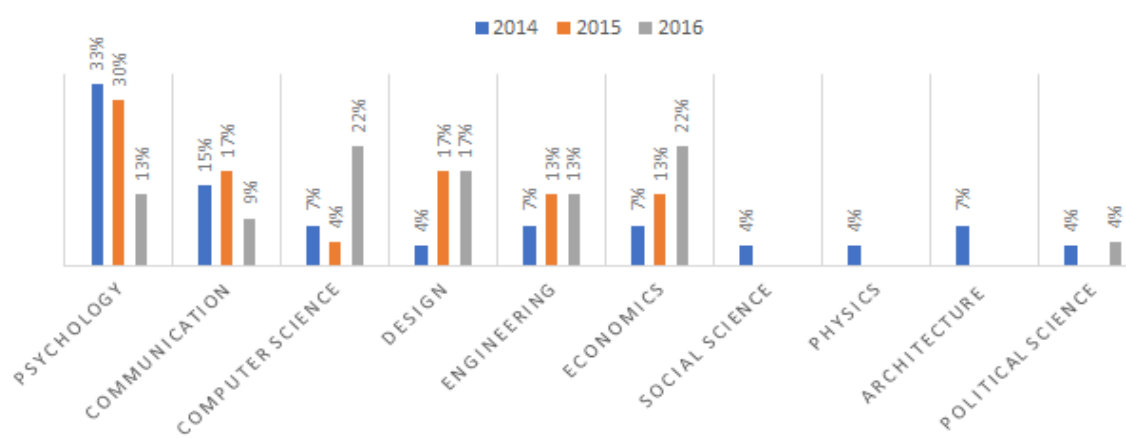

Figure 4. Speakers of the Turin WUD 2014-2016 - Affiliation (Source: SIE Piemonte)

\section{AFFILIATION}

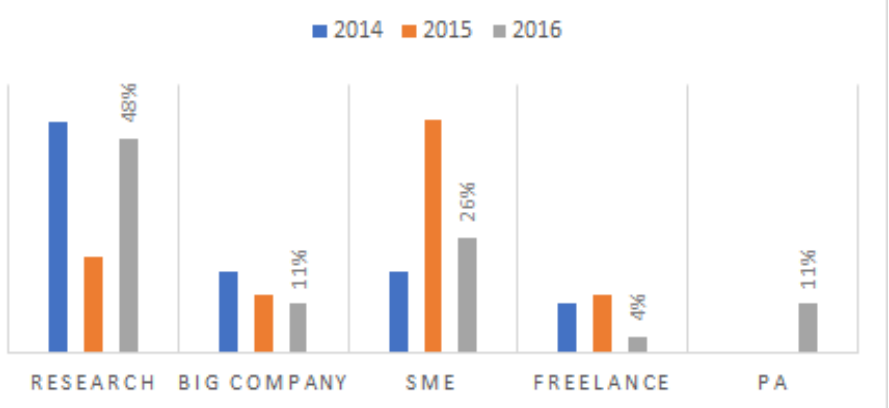


Information collected about the audience shows that in 3 years about 300 people participated to the WUDs, with a slight majority of female presence (Fig. 5). The background reflects the same speakers' distribution, with a higher presence of psychologists and communication scientists, except for the third edition, where the computer scientists represent the largest group (Fig.6). This peak has to be read in combination with the important presence of students, and both data can be explained by the role that the University of Turin played into the organization. The most part of participants comes from research institutions. The big companies and SMEs presence results quite stable, with the exception of the third edition, dedicated to the topic of sustainable design and in particular to the circular economy, topic of great relevance for

Figure 5. Audience of the Turin WUD 2014-2016. Gender (Source: SIE Piemonte)

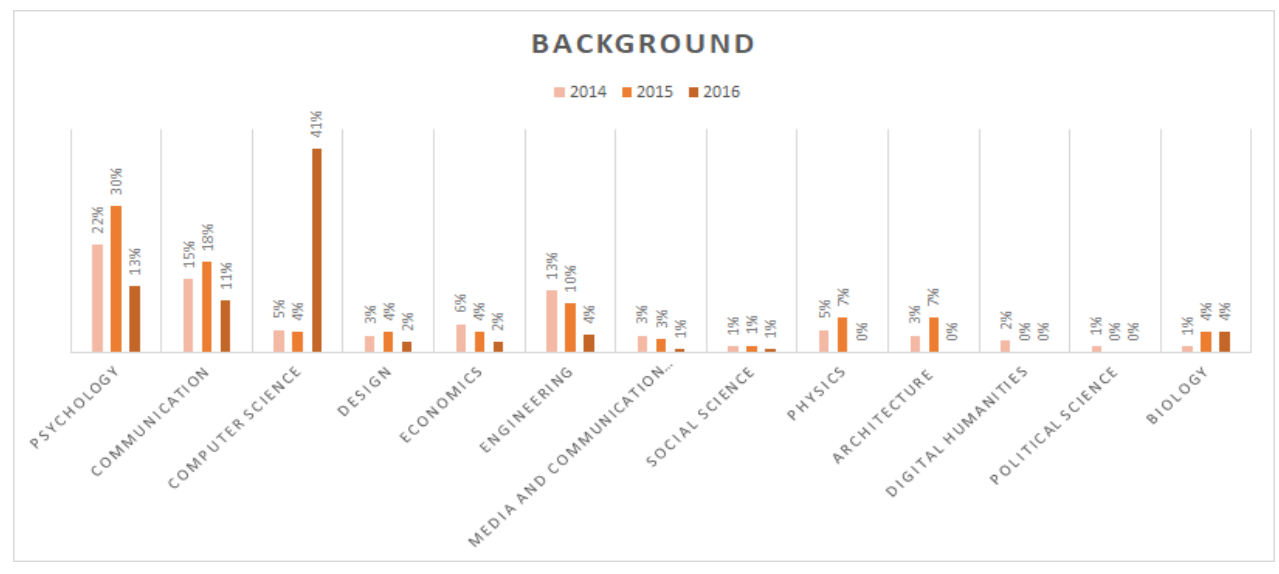

Figure 6. Audience of the Turin WUD 2014-2016. Background (Source: SIE Piemonte)

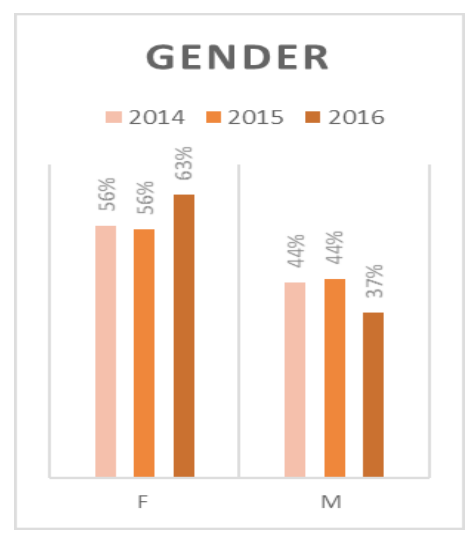

PA, significantly increasing their presence compared to previous years (Fig.7). 
Figure 7. Audience of the Turin WUD 2014-2016. Affiliation (Source: SIE Piemonte)

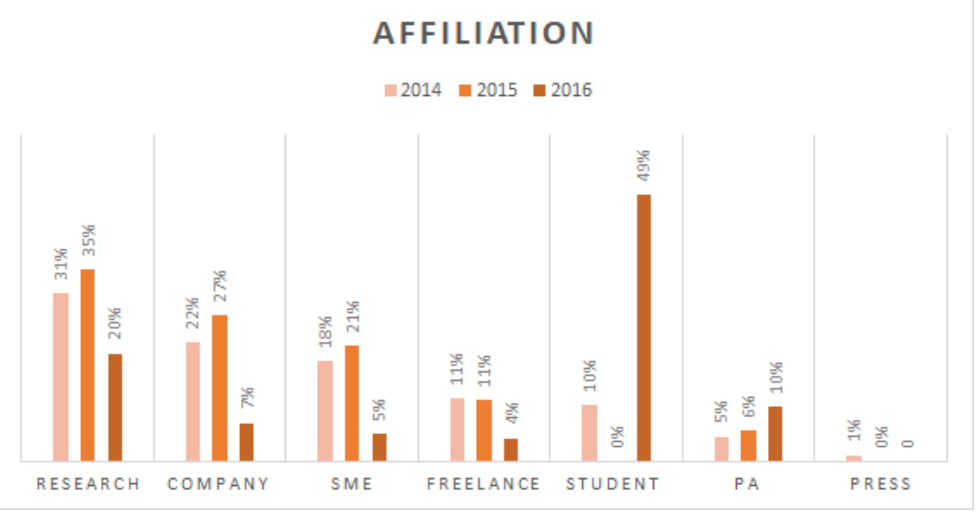

\section{Motivations of the community}

At the end of each Turin WUD edition, all participants have been invited to fill in a satisfaction survey. The questionnaries are anonymous and filled on voluntary base and asked an evaluation of the program proposed, as well as some questions investigating the participants motivations and the value they get from the event. The satisfaction surveys have been designed not for research purposes, but the extraction of relevant data allow to have a rough idea of the needs of the community and of the gaps to focus on in future editions. At the end of each event about the $40 \%$ of participants replied to the satisfaction survey.

Among the motivations that pushed people to participate, the interest of the proposed topics is the most relevant, followed by the possibility to follow workshops with professionals (Fig.8). Respondents consider the quality of speeches and network interesting factors, but unexpectedly not crucial. The possibility to make experience and work to put in practice the proposed novelties depicts a very committed community, interested in exploring novel fields and keep on learning and doing.

The data positively match with the overall evaluation of the events, reporting good levels of satisfaction (Fig.9).

Figure 8. Motivations to participate to Turin WUD. (Source: SIE Piemonte)

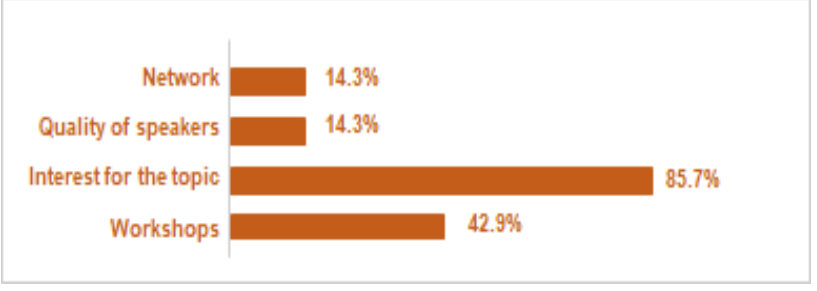


Figure 9 - Satisfaction survey results on the Turin WUD (Source: SIE Piemonte)

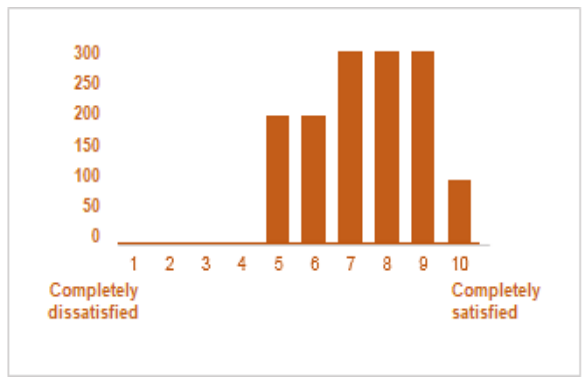

Reported factors of satisfaction are the quality of the speeches/speakers (91\%) ("quality of the contents", "the richness and variety of different approaches and perspectives presented", "the variety of the topics"), followed by the possibility to follow one or more workshops and finally the networking: "the excellent opportunity to exchange and deepen themes related the UX"; "the chance to meet people with different skills who do jobs similar to yours".

The most important suggestion received on improvements concerns the time schedule of the agenda: if from one side a rich full-day program is interesting and attractive, from the other side, it implies restricted times to deepen contents with questions and discussions both with speakers and among participants.

\section{Common principles}

An important information gathered in these years is represented by the contributions presented. A content analysis has been made to search and collect UX definitions and references applied by different organizations, as well as common theoretical models and methodologies, to identify in which phases of the process the UX enters and is exploited. The content analysis has been conducted on the abstracts of the speeches and posters presented in 3 years.

The first level of analysis allowed to identifies the most relevant areas of interest and relevant concepts, shown as keywords in the tag cloud, where the size of the words is proportional to the recorded frequency (Fig.10).

The most part of the talks reported deal with UX applied to services and applications. Technology has always been analysed as enabling factor and object of design and development. Analysing the presented projects and experiences, it is possible to identify at what stadium the UX enters and to what extent methods and techniques of user research and user testing are applied (Fig.10). 
Figure 10. Word cloud of the Turin WUD 2014-2016 contents (Source: SIE Piemonte)

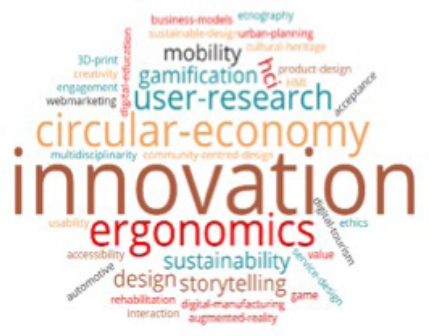

These data suggest that currently the user experience is mainly applied to the phase of devepment and production (fig. 11). It does not appear as it could in the early stages of an innovation process. The user research, based on qualitative and quantitative investigation of the target users, is mostly applied in research contexts (Fig. 12 and 13). When the topic of interest and the field of work tend to overlap with other domains (as in the case of circular economy domain), the Human Centred Design is not yet properly applied and the activities of user studies and participatory design are considered at a theoretical level and not well integrated into the processes.

Figure 11. Level of maturity of the experiences presented at Turin WUD 2014-2016 (Source: SIE Piemonte)

LEVEL OF READINESS OF

EXPERIENCES

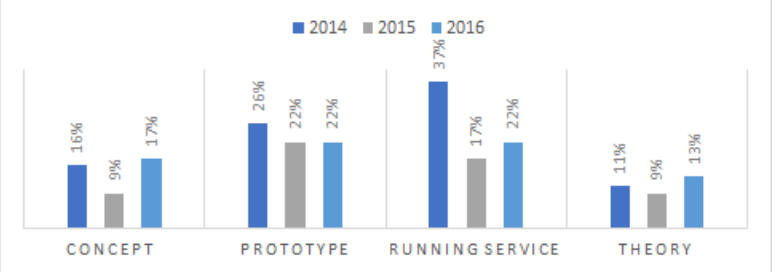

Figure 12 and 13. User activities reported at Turin WUD 2014-2016 (Source: SIE Piemonte)

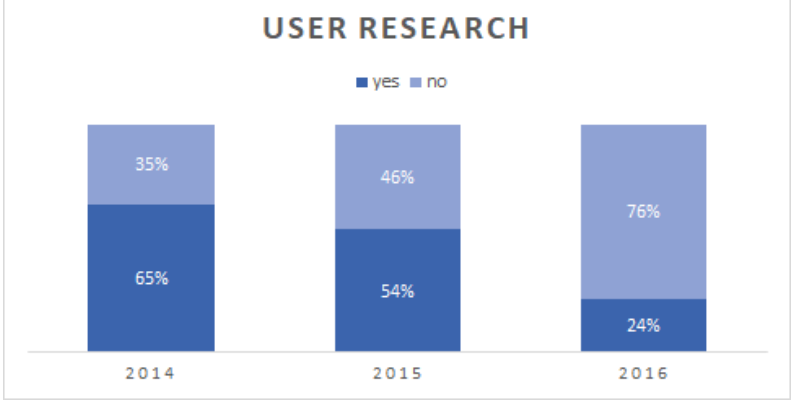




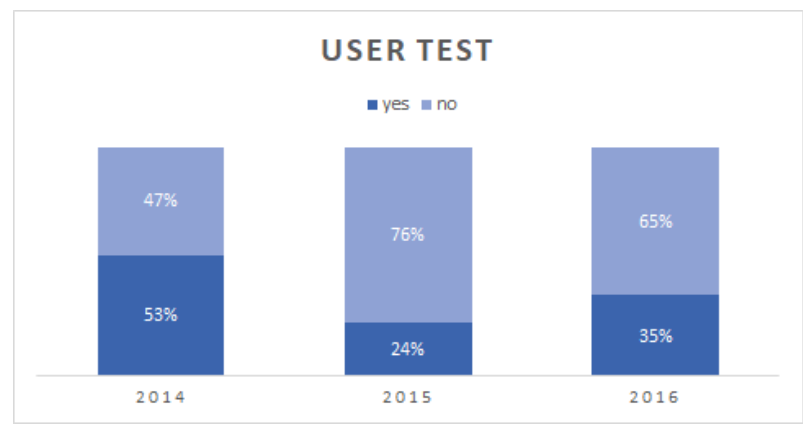

\section{New initiatives: WUD Milan and the italian network}

On the base of the success of the WUD-TURIN, both in terms of participation and "inspiration", the SIE Group of Interest in Cognitive ergonomics decided to promote WUD in Milan as well. At its second edition, WUD-Milan is organized by the University of Milano-Bicocca together with Avanade-Italy and, from 2017, Microsoft-Italy. With the same spirit of WUD-Turin, the first edition - "WUD-Milan 2016. Sustainable UX: the Italian Way" - has been hosted by "Talent Garden", a space for co-working and networking with a particular attention for ecological and sustainable design. With 18 speakers coming from different realities - such as the Accessibility team for IBM-Italy, the Government Agency for Digital Italy or the digital platform "Fight the Stroke" - and an enthusiastic participation of a heterogenous audience, the event has become a reference event for the UX community in Milan, involving important education institutions and companies active in a very dynamic city. In 2017 the event was organized in two-days (following the suggestions given by participants) and hosted in the Microsoft-House, a space in the core of the city opened by Microsoft with the mission of "innovation, collaboration, finding new ideas and build an ecosystem". The two days event has been dedicated to Accessibility in terms of the total absence of physical and psychological barriers not only in works, cities and public spaces but also in fields as entertainments, fashion and sport.

Finally, the project of the Italian WUD-Diffuse Network has been taken off. The success of the Turin and Milan WUDs, together with the involvement of national scientific societies such as the Italian Society of Ergonomics and the Italian Chapter of ACM Group of interest in Human Computer Interaction (SIG CHItaly), has led to the project of a larger network aimed at bringing events on UX and Human Centred Design in Italy. We have just started to join in our group also the WUD-Rome, trying to connect the diverse aspects of UX as it is developed at different local realities (which is particularly significant in Italy when considering the huge difference between the North and the South of the country). Besides connecting a larger community of UX professionals and researcher, we think that the World Usability Day could also be an optimal observatory for inspiring new solutions for a better life, also in terms of active citizenship.

\section{Discussion and conclusion}

The WUD initiative has represented and keeps on being an important opportunity to observe research and professional practices on UX as intertwined areas of activity. The events till now organized highlight the spread of UX in sectors that were previously very distant from this topic. In our experience, it was significant to see, for example, Public Administration entering into the debate. Furthermore, it emerges clearly how in very different fields, from academical research to advertising, from automotive to health services, economy, education, there are useful points of contact in terms of methodologies and tools. From the organizers' perspective, it is interesting pointing on how a number of overlapping aspects can find a solution through the 
knowledge sharing: often the lexicon traces differences that can be overcome by recognizing similar practices.

Providing a space of exchange to a very heterogeneous audience can be very complex. First of all, because of the need to establish a common base of concepts and knowledge. Face to face events represent effective opportunities to set up a network of people different in background, interests, age, profession, that accepts the challenge of work on 'niche' topics such as user experience, usability and ergonomics.

From the Turin WUD, several side initiatives were born, such as joint projects and jobs opportunities. Moreover, it launched other dissemination activities. Finally, it was also source of inspiration for other activities, as the WUD-Italian Network. This objective is especially focused on the need to enhance the interaction between territory and academy: the choice of WUD locations and the creation of a widespread network until now has succeed to encourage the dialogue between universities and companies. Furthermore, it aims to involve more and more young people in the world of $\mathrm{UX}$, ergonomics and $\mathrm{HCl}$, favouring the job placement, promoting the economic development under a wider humanistic and at the end multidisciplinary perspective.

\section{BIBLIOGRAPHICAL REFERENCES}

- Bader, F., Schön, E.M., Thomaschewski, J. Heuristics Considering UX and Quality Criteria for Heuristics. International Journal of Interactive Multimedia and Artificial Intelligence 4:48-53, Dec. 2017.

- Bloc Blog. Job Trends Report: The Job Market for UX/UI Designers, 2015. Retrieved the November 2017 from: https://blog.bloc.io/job-market-for-ux-ui-designers

- Law, E.L., Vermeeren, A P.O. S. Hassenzahl, M. and Blythe, M. 2007. Towards a UX manifesto. In Proceedings of the 21st British $\mathrm{HCl}$ Group Annual Conference on People and Computers: HCl...but not as we know it - Volume 2 (BCS-HCl '07), Vol. 2. BCS Learning \& Development Ltd., Swindon, UK, 205-206.

- Franzreb, D and Franzreb P. Designing With Human Centered Usability Standards, UXBooth, 2016. http://www.uxbooth.com/articles/designing-usability-standards

- Garrett, J.J. The Elements of User Experience. 2011. Berkeley, CA: New Riders

- Hassenzahl M. \& Tractinsky, N. 2006. User experience - a research agenda, Behaviour \& Information Technology, 25:2, 91-97

- IEA - International Ergonomics Association. http://www.iea.cc/whats. Retrieved in November 2017 from:

- ISO 9241:2010. Ergonomics of human-system interaction - Part 210: Human-centred design for interactive systems (formerly known as 13407). International Organization for Standardization (ISO). Switzerland.

- $\quad$ Labarre, S. The Most Important Design Jobs Of The Future. FastCompany, 2017. Retrieved in November 2017 from: https://www.fastcodesign.com/3054433/the-most-importantdesign-jobs-of-the-future

- $\quad$ Lachner, F. Naegelein, P. Kowalski, R. Spann, M. and Butz. A: 2016. Quantified UX: Towards a Common Organizational Understanding of User Experience. In Proceedings of the 9th Nordic Conference on Human-Computer Interaction (NordiCHI '16). ACM, New York, NY, USA, Article 56.

- Malouf, D. 2016. The Guide to UX Leadership. UX Pin.

- Mayhew, D.J. User Experience Design: The Evolution of a Multi-Disciplinary Approach. Journal of Usability Study, Vol. 3, Issue 3, May 2008, pp. 99-102.

- Milburn, T., Bouwmeester, M., Carbaugh, D., et al. 2015. Communicating User Experience: Applying Local Strategies Research to Digital Media Design. Lexington Books.

- Nielsen, J. Discount Usability: 20 Years, 2009. Retrieved the 30 nov. 2017 from: https:// 
www.nngroup.com/articles/discount-usability-20-years

- $\quad$ Norman, D.A., Draper. S.W. 1986. User Centered System Design; New Perspectives on Human-Computer. Interaction. L. Erlbaum Assoc. Inc., Hillsdale, NJ, USA.

- Norman, D.A.. 2002. The Design of Everyday Things. Basic Books, New York, NY, USA.

- Olson, J.S. and Kellogg, W.A. 2014. Ways of Knowing in HCl. Springer.

- $\quad$ Roto, V., Law, E., Vermeeren, A., Hoonhout, J. User Experience White Paper, 2011. Retrieved the 28 Nov. 2017, from: http://www.allaboutux.org/files/UX-WhitePaper.pdf

- Solomon, G.E.A. Carley, S. and Porter, A.L. How Multidisciplinary Are the Multidisciplinary Journals Science and Nature? PLoS One. 2016; 11(4): e0152637.

\section{NOTES}

(1) IEA - International Ergonomics Association: http://www.iea.cc

(2) Google Design Sprint Kit: designsprintkit.withgoogle.com

(3) www.societadiergonomia.it

(4) uxpa.org

(5) worldusabilityday.org/about-wud

(6) en.wikipedia.org/wiki/World_Usability_Day

\section{ACKNOWLEDGEMENTS}

This work was realized thanks to people and institutions that have organized the Turin World Usability Days: Silvia Gilotta, SIE; Rossana Actis-Grosso, University of Milano-Bicocca; Gabriella Duca, ISSNOVA; Elena Guercio, Antonella Roella and Silvia Bonaventura, TIM; Cristina Gena, University of Turin; Massimo Zancanaro, FBK, President of SIG CHItaly. We also thank Francesca Tassistro and Silvia Soccol, and the group of Avanade-Italy, for their invaluable help in organizing Wud-Milan.

\section{CURRICULUM VITAE}

Antonella Frisiello, is Master Degree in Psychology and Master Science in Ergonomics. Currently works at ISMB, an Italian Research Centre on Innovation Technology as User Experience Researcher, in National and European research projects focusing on the design, development and assessment of innovative and people-inspired services. From 2017 she is member of the Observatory of Communication, Videogames and Entertainment of the Universidad Autónoma de Barcelona (OCVE - incom-uab.net/ocve/es/ocve). From the 2014 to 2017 she was Regional President of SIE, the Italian Society of Ergonomics and founder of the WUD - World Usability Day Turin.

Rossana Actis Grosso, is Associate Professor at the University of Milano-Bicocca, where she teaches Cognitive Ergonomics. She obtained a PhD in Experimental Psychology (University of Padova). Her research interests are mainly focused on visual perception and $\mathrm{HCl}$. She is author of several publications on these topics and served as reviewer for numerous journals and international conferences. She is member of several societies and part of the executive committee of the Italian Society for Ergonomics. She is responsible of the centre for external consultancy (to a third part) service (BtoU) of the University of Milano-Bicocca for usability and User-Experience evaluations. 


\section{ENSAYOS_ESSAYS}
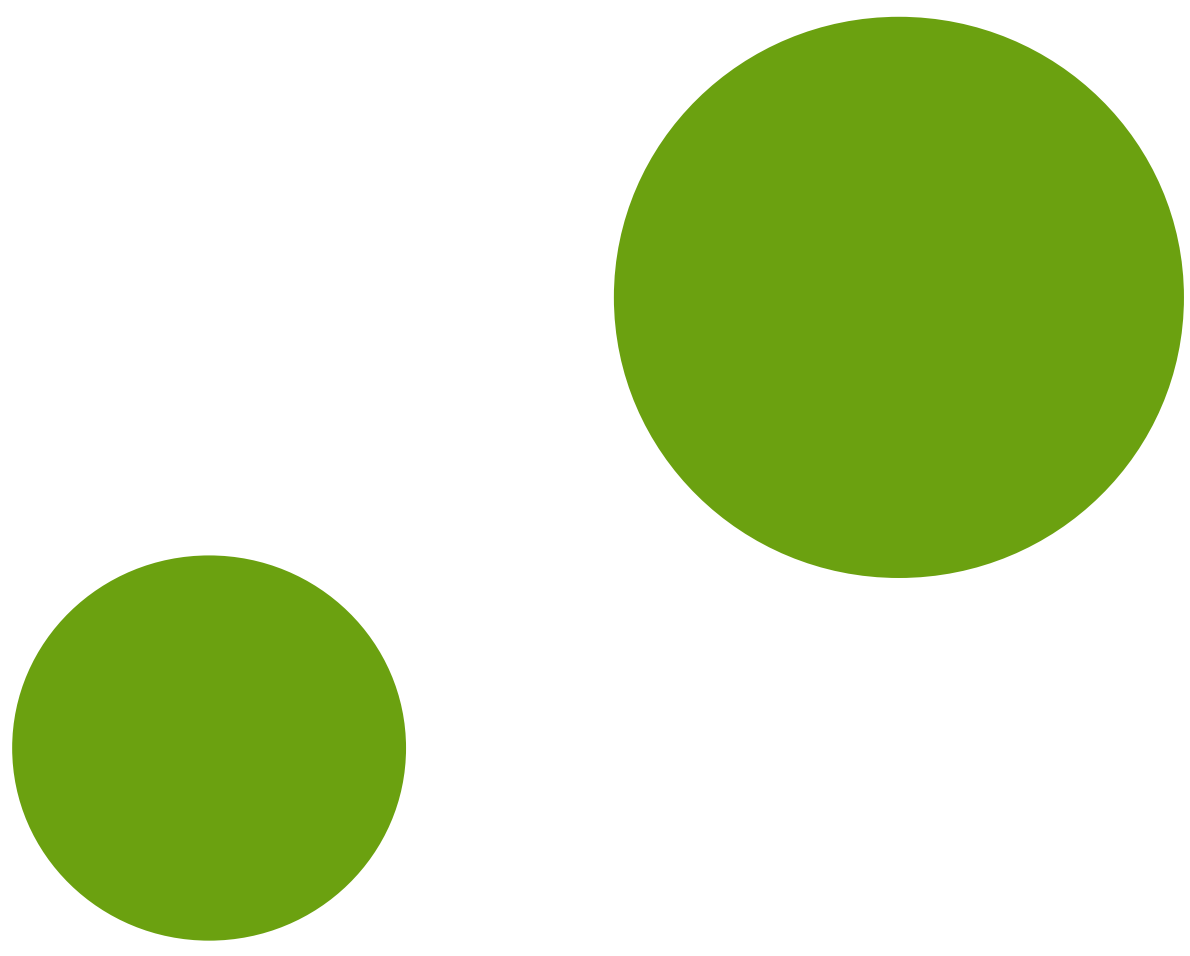
